\title{
Morphological characteristics predict postoperative outcomes after vitrectomy in myopic traction maculopathy patients
}

\section{Tian-Qi Duan}

Xiangya Hospital Central South University

\section{Kun Song}

Xiangya Hospital Central South University

Jie Yang

Xiangya Hospital Central South University

\section{Fang-Ling Li}

Xiangya Hospital Central South University

\section{Si-Qi Xiong}

Xiangya Hospital Central South University

\section{Xiang-Gui Wang}

Xiangya Hospital Central South University

Hui-Zhuo Xu ( $\nabla$ nikk1235@163.com )

Xiangya Hospital Central South University

\section{Research article}

Keywords: morphological characteristics, anatomical recovery, best-corrected visual acuity, central retinal thickness, myopic traction maculopathy

Posted Date: September 24th, 2019

DOI: https://doi.org/10.21203/rs.2.14742/v1

License: (c) (1) This work is licensed under a Creative Commons Attribution 4.0 International License. Read Full License

Version of Record: A version of this preprint was published at Ophthalmic Surgery, Lasers and Imaging Retina on October 1st, 2020. See the published version at https://doi.org/10.3928/23258160-2020100505. 


\section{Abstract}

AIM To provide the surgical indication for patients with myopic traction maculopathy (MTM) by investigating the postoperative outcomes after vitrectomy among different types of morphological characteristic groups.

METHODS All the 37 eyes of 37 MTMs were classified into three groups: foveal retinoschisis (FS), lamellar macular hole (LMH), foveal retinal detachment (FRD). The ratios of anatomic recovery, the central retinal thickness (CRT) and the best corrected visual acuity (BCVA) were statistically analyzed among the three groups at preoperatively and followed up on 1, 3, 6 and 12 months after vitrectomy.

RESULTS Anatomical recovery could be found in all patients of the FS and LMH group at 6 and 12 months postoperatively, respectively, but only $83.33 \%$ patients in the FRD group showed anatomic recovery until 12 months. The time of CRT reduced to $200 \mu \mathrm{m}$ at 1, 6 and 12 months in FS, LMH and FRD group separately. Postoperative BCVA was better in the FS group than LMH and FRD group $(P<0.05)$, but $\mathrm{LMH}$ group and FDR group had no difference. The visual acuity was significantly improved in FS group $(P<0.01)$ and FRD group $(P=0.018)$, but not the LMH group $(P=0.196)$.

CONCLUSION The FS group approached to anatomical recovery firstly gets the best BCVA. Early surgery should be considered for eyes at FS and before LMH or FRD occurs.

\section{Background}

Myopic traction maculopathy (MTM) is one of the major causes of poor vision in eyes with pathological macular lesions associated with high myopia, which are caused by traction and are discovered in 9 to $34 \%$ of high myopia and posterior staphylomas [1-4]. The vision suffers damage when MTM present manifestation including thickening of the retina, macular retinoschisis-like structures, foveal retinal detachment and macular holes. There are many factors may affect the development of MTM $[2,5,6]$, but the pathogenesis is not clear. Recently some studies have reported that it may be related to the adherent vitreous cortex, epiretinal membrane, internal limiting membrane (ILM), retinal blood vessels, axis lengthening, and formation of posterior staphyloma [7-10].

Vitrectomy combined with ILM peeling[11-13], posterior scleral reinforcement [14-16], intraocular gas treatment [17], and combination of these approaches [18] is considered to be effective treatment for MTMs. Among these methods, vitrectomy combined with ILM peeling for MTMs has good visual and anatomic results and perceived as the preferred treatment [19-21]. Recently, some scholars [22, 23] have found that collagen fibers and cellular components on the intimal membrane may play an important role in the formation of macular cleavage. Therefore, some researchers preferred vitrectomy combined with fovea-sparing ILM peeling for reducing the occurrence of secondary macular holes [24,25]. On the basis of the appeal study, we chose vitrectomy combined with ILM peeling and C3F8 tamponade, and foveasparing ILM peeling in patients with foveal detachment and thinned retina. 
Preoperative visual acuity, the foveal status, duration of symptoms, age are important factors affect postoperative visual acuity in the treatment of MTM $[11,26]$. Optical coherence tomography (OCT) is a useful way to diagnose MTM and monitor the development of MTM. Many investigators have attempted to observe the postoperative results in different types of MTM $[11,27]$ according to OCT and tried to find out the indications for surgery. There is no standard of indication for surgery, and it's controversial about whether FS should be as a candidate for surgery[11, 26, 28, 29]. Nevertheless, these studies only compared the final results of MTM patients at some point after surgery and didn't report the anatomical and visual recovery speed among different morphological type of MTMs. In this study, we retrospectively analyzed 37 patients were diagnosed as MTM, and classified these 37 eyes into three groups: foveal retinoschisis $(\mathrm{FS})$, lamellar macular hole $(\mathrm{LMH})$, foveal retinal detachment $(\mathrm{FRD})$. We compared the results of different morphological type of MTM patients at 12 months after surgery, and analyzed the process of splitting healing and visual acuity improvement preoperatively and 1,3,6, and 12 months after vitrectomy with ILM peeling and C3F8 tamponade. Our research performed the correlation between the morphological characteristics and anatomical and visual outcomes after vitrectomy in MTMs and provided the surgical indications of MTM.

\section{Methods}

\section{Ethical Approval}

Each patient received and agreed with written informed consent for examination and surgery. This study followed all tenets of the Declaration of Helsinki and approved by the Institutional Review Committee of Xiangya Hospital of Central South University.

\section{Data Source and Study of Population}

Subjects were adults who diagnosed as MTM by comprehensive eye exam, including BCVA, fundus photography, OCT (Zeiss, Germany), and axial length assessments (IOLMaster; Zeiss, Germany) and underwent vitrectomy combined with ILM peeling and C3F8 tamponade from January 2017 to January 2019 at Xiangya Hospital of Central South University.

The eyes were categorized into three types based on their foveal OCT findings: foveal retinoschisis (FS), lamellar macular hole (LMH), foveal retinal detachment (FRD). The FS group had foveal retinoschisis-like structures without photoreceptor detachment from the retinal pigment epithelium or intraretinal splits, the LMH group had foveal intraretinal splits without photoreceptor detachment from retinal pigment epithelium, and the FRD group had photoreceptor detachment from the retinal pigment epithelium at the fovea.

\section{Statistical Analysis}


Patient demographic data, foveal OCT findings, and BCVA of each foveal type were compared retrospectively. All statistical analyses were performed using IBM SPSS, version 19 (IBM Corp, USA). Data were presented as means \pm standard deviation (SD), and differences were considered significant if $P$ $<0.05$.

\section{Results}

The basic information of patients (Table 1) shows that there was no significant difference in preoperative parameters including sex, age, and eye axis among the three groups. And we found that the visual acuity of the FS group was significantly better than LMH $(P<0.05)$ and FRD group $(P<0.01)$. However, there was no significant difference in visual acuity between the FRD and LMH groups $(P=0.056$; Fig. 1$)$.

Anatomical recovery could be found in all patients of the FS and LMH group at 6 and 12 months postoperatively, respectively, but only $83.33 \%$ patients in the FRD group showed anatomic recovery until 12 months (Table 2). Fig. 2 and Fig. 3 show the CRT of macular area preoperatively and postoperatively of these three groups. Not only the preoperative splitting height was lower in the FS group than in FRD and LMH groups, but also at 1, 3, 6 and 12 months of follow-up, although the splitting height have no significantly differ between FRD and LMH groups (Fig. 3). The average CRT of FS group decreased to 200 $\mu \mathrm{m}$ at 1 month postoperatively, and that of LMH and FRD group decreased to $200 \mu \mathrm{m}$ at 6 months and 12 months postoperatively, respectively.

The BCVA of the FS group was significantly better than FRD and LMH group at preoperative, 1 month, 3 months, 6 months and 12 months (Fig. 4A; B) of follow-up. The visual acuity was significantly improved at the end of follow-up at 12 months of FS group $(P<0.01)$ and FRD group $(P=0.018)$. Visual improvement was not significant in the LMH group ( $P=0.196$, Fig. $4 C)$.

\section{Discussion}

At the postoperative 1 month follow-up, we found significant differences among the three groups in the anatomic reduction rate (FS: 53.85\%; FRD: 9.1\%; LMH: 50\%). At the end of 12 months of follow-up period, we found there was no significant differences among the three groups in the reduction rate (FS: $100 \%$; FRD: $83.33 \%$; LMH: 100\%). Combining the results of preoperative mean CRT: the highest in the FRD group and lowest in the FS group before surgery. At the 12-month follow-up, the mean CRT showed the same relationship. Studies have shown that the average foveal thickness in normal Asians ranges from 195 to $252.8 \mu \mathrm{m}$ [30-32]. We hypothetically used $200 \mu \mathrm{m}$ as the boundary for splitting improvement in patients with high myopia, and anatomic recovery was consistent with the reduction of CRT in each group.

Shinohara et al. showed that outer retinoschisis is mainly caused by a posteriorly pulling force, that is, the staphyloma, and the inner retinoschisis is caused mainly by an anteriorly pulling force, that is, vitreous traction and vascular microfolds. The larger the pulling force is the higher the CRT[3,33]. When the anteriorly pulling force is surgically removed, the FRD group showed the slowest recovery during 12 months follow-up period, followed by the LMH group, while the FS group with the smallest pulling force 
showed the fastest recovery. The splitting can heal eventually as the pull force relieving. Therefore, at the end of the follow-up period the splitting height of all these eyes decreased and reached under $200 \mu \mathrm{m}$. To be sure, splitting recovery in FS group was the fastest, followed by LMH group, slowest in FRD group.

In FS group, as the anatomical reduction the postoperative BCVA reached to a satisfactory level early and maintained the good vision after surgery. But the visual acuity of the LMH and FRD group did not significantly improve even though splitting gradually recovered. We find the preoperative BCVA and CRT was positively correlated with the postoperative BCVA was certified and same with previous study [23]. FS group had the best preoperative and postoperative vision[26, 34]. It could be understood because there is less photoreceptor and neuroepithelial damage in the FS group than LMH group and FRD group, and most of photoreceptor could work again after anatomical recovery in FS group. Surgery only helps for anatomical recovery, not for retinal nerve fiber layer repairing in fovea. Thus, like the result of KYOKO's investigation [27]and our results that the visual acuity of the LMH group did not significantly improve even though splitting gradually recovered, LMH visual outcome was not good after surgery. Baba et al [3] suggested that if shallow retinal detachment lasts long, the damage to the photoreceptors is likely to progress, consequently leading to decreased vision. Ohno-Matsui et al[35]proposed that photoreceptor layer defects and persistent chorioretinal degeneration may be the mechanism underlying unsatisfactory postoperative visual recovery and outcome. Thus, when the photoreceptor layer of FRD is separated from the RPE layer, resulting in the damage of photoreceptor cells associated with vision due to lack of nutrition [35]. Here, the visual improvement of FRD was worse than FS group, was different with Yasushi's description [11]. It may relate to the small sample size and the long time for duration of symptoms in FRD group. In general, although there was no dramatic improvement in visual acuity of LMH, they all can reach anatomical recovery after vitrectomy and prevent the progression of MTM.

It is still controversial to determine the optimal timing for MTM, and the selection of surgical candidates based on the judgments of operators. Some people believed FRD was a predictive factor of poor prognosis, and suggested early surgery should be performed in MTM before FRD appearing[11, 36, 37]. However, there is another opinion pointed out the presence of FRD should be considered for surgical indication[27]. Here, we concluded FS group got the fastest anatomical recovery, reached the best visual acuity, and gained the largest visual improvement compared the slower anatomical recovery and the poor visual outcome in LMH and FRD group. We consider early surgery for FS whenever the patient had visual loss before the LMH or FRD occurs.

Development of full-thickness macular hole $(\mathrm{MH})$ from FS and LHM were observed in previous researches[38]. It's known $\mathrm{MH}$ lead to poor prognosis, most $\mathrm{MH}$ could not gain visual improvement even after surgery, and the purpose of surgery for $\mathrm{MH}$ was to avoid a worse prognosis [11, 26]. In our observation, we lacked of $\mathrm{MH}$ patients because $\mathrm{MH}$ patients lost fellow-up after surgery. We hypothesis their poor visual outcome after surgery resulted in the high missing rate. But the loss of MH didn't influence our conclusion because we can speculate the benefit of MH was less than LMH and FRD. Some investigation showed duration of symptoms is a significant predictive factor for visual outcomes after surgery [11], it's a deficiency of no recorders about the duration of symptoms in our study. In addition, we 
will enlarge sample and compare the outcomes among more different morphological characteristics in the future.

\section{Conclusions}

In summary, our study showed that the splitting healing rate was the fastest in the FS group, followed by LMH group, slowest in FRD group. Consistently, the FS group achieved the best BCVA in the shortest timeframe among the three groups, and the patients in the FRD and LMH groups might have poor visual acuity after the operation. Thus, morphological characteristics could be an important indicator for prognosis after surgery and as surgical indications for MTMs. Early surgery should be considered for eyes at FS and before LMH or FRD occurs.

\section{Abbreviations}

MTM - myopic traction maculopathy

FS - foveal retinoschisis

LMH - lamellar macular hole

FRD - foveal retinal detachment

CRT- central retinal thickness

BCVA - best corrected visual acuity

ILM - internal limiting membrane

OCT - Optical coherence tomography

\section{Declarations}

\section{Acknowledgements}

Thanks for all the supports and contributions of participators.

\section{Authors' contributions}

Study concept and design (DTQ, SK); data collection (YJ, DTQ, SK, LFL); analysis and interpretation of data (XSQ, WXG); drafting of the manuscript (DTQ, SK); critical revision of the manuscript (DTQ, SK, YJ); supervision $(\mathrm{XHZ})$. All authors have read and approved the whole manuscript and the publication. 


\section{Funding}

This work was supported by the Natural Science Foundation Surface Project of Hunan Province (Grant No. 2019JJ40528).

\section{Availability of data and materials}

The datasets used or analyzed during the current study are available from the corresponding author on reasonable request.

\section{Ethics approval and consent to participate}

Each patient received and agreed with written informed consent for examination and surgery. This study followed all tenets of the Declaration of Helsinki and approved by the Institutional Review Committee of Xiangya Hospital of Central South University.

\section{Consent for publication}

Written informed consent was obtained from the patients for publication of this article and any accompanying images. A copy of the written consent is available for review by the Editor of this journal.

\section{Competing interests}

The authors declare they have nothing worthy disclosure.

\section{References}

1.Takano $\mathrm{M}$, and Kishi S. Foveal retinoschisis and retinal detachment in severely myopic eyes with posterior staphyloma. Am J Ophthalmol. 1999;128:472-476.

2.Panozzo G, and Mercanti A. Optical coherence tomography findings in myopic traction maculopathy. Arch Ophthalmol. 2004;122:1455-1460.

3.Baba T, Ohno-Matsui K, Futagami S, Yoshida T, Yasuzumi K, Kojima A, Tokoro T, and Mochizuki M. Prevalence and characteristics of foveal retinal detachment without macular hole in high myopia. Am J Ophthalmol. 2003;135:338-342.

4.Ouyang PB, Duan XC, and Zhu XH. Diagnosis and treatment of myopic traction maculopathy. Int J Ophthalmol. 2012;5:754-758. 
5.Wu PC, Chen YJ, Chen YH, Chen CH, Shin SJ, Tsai CL, and Kuo HK. Factors associated with foveoschisis and foveal detachment without macular hole in high myopia. Eye (Lond). 2009;23:356-361.

6.Li Y, Miara H, Ouyang P, and Jiang B. The Comparison of Regional RNFL and Fundus Vasculature by OCTA in Chinese Myopia Population. J Ophthalmol. 2018;2018:3490962.

7.Panozzo G, and Mercanti A. Vitrectomy for myopic traction maculopathy. Arch Ophthalmol. 2007;125:767-772.

8.VanderBeek BL, and Johnson MW. The diversity of traction mechanisms in myopic traction maculopathy. Am J Ophthalmol. 2012;153:93-102.

9.Ikuno Y, Gomi F, and Tano Y. Potent retinal arteriolar traction as a possible cause of myopic foveoschisis. Am J Ophthalmol. 2005;139:462-467.

10.Shimada N, Ohno-Matsui K, Nishimuta A, Moriyama M, Yoshida T, Tokoro T, and Mochizuki M. Detection of paravascular lamellar holes and other paravascular abnormalities by optical coherence tomography in eyes with high myopia. Ophthalmology. 2008;115:708-717.

11.Ikuno Y, Sayanagi K, Soga K, Oshima Y, Ohji M, and Tano Y. Foveal anatomical status and surgical results in vitrectomy for myopic foveoschisis. Jpn J Ophthalmol. 2008;52:269-276.

12.Ikuno Y, Sayanagi K, Ohji M, Kamei M, Gomi F, Harino S, Fujikado T, and Tano Y. Vitrectomy and internal limiting membrane peeling for myopic foveoschisis. Am J Ophthalmol. 2004;137:719-724.

13.Zheng B, Chen Y, Chen Y, Zhao Z, Zhang Z, Zheng J, You Y, Wang Q, and Shen L. Vitrectomy and internal limiting membrane peeling with perfluoropropane tamponade or balanced saline solution for myopic foveoschisis. Retina. 2011;31:692-701.

14. Ward B, Tarutta EP, and Mayer MJ. The efficacy and safety of posterior pole buckles in the control of progressive high myopia. Eye (Lond). 2009;23:2169-2174.

15.Zhu Z, Ji X, Zhang J, and Ke G. Posterior scleral reinforcement in the treatment of macular retinoschisis in highly myopic patients. Clin Exp Ophthalmol. 2009;37:660-663.

16.Baba T, Tanaka S, Maesawa A, Teramatsu T, Noda Y, and Yamamoto S. Scleral buckling with macular plombe for eyes with myopic macular retinoschisis and retinal detachment without macular hole. Am J Ophthalmol. 2006;142:483-487.

17.Gili P, Yanguela J, and Martin JC. Intraocular gas treatment for myopic foveoschisis. Eur J Ophthalmol. 2010;20:473-475.

18.Xiong SQ, Jiang HB, Li FL, Li YX, Yang J, Xia XB, and Xu HZ. Treatment of myopic foveoschisis via macular buckling and vitrectomy. Int J Ophthalmol. 2017;10:815-818. 
19.Kobayashi H, and Kishi S. Vitreous surgery for highly myopic eyes with foveal detachment and retinoschisis. Ophthalmology. 2003;110:1702-1707.

20.Futagami S, Inoue M, and Hirakata A. Removal of internal limiting membrane for recurrent myopic traction maculopathy. Clin Exp Ophthalmol. 2008;36:782-785.

21.Liu H, Zuo S, Ding C, Dai X, and Zhu X. Comparison of the Effectiveness of Pars Plana Vitrectomy with and without Internal Limiting Membrane Peeling for Idiopathic Retinal Membrane Removal: A MetaAnalysis. J Ophthalmol. 2015;2015:974568.

22.Bando H, Ikuno Y, Choi JS, Tano Y, Yamanaka I, and Ishibashi T. Ultrastructure of internal limiting membrane in myopic foveoschisis. Am J Ophthalmol. 2005;139:197-199.

23.Song $M$, Shen $M$, Zhou Y, Zheng K, Zhai Y, Xiao M, Wang X, Wang F, and Sun X. Observation of Vitreous Features Using Enhanced Vitreous Imaging Optical Coherence Tomography in Highly Myopic Retinoschisis. Retina. 2018;

24.Shimada N, Sugamoto Y, Ogawa M, Takase H, and Ohno-Matsui K. Fovea-sparing internal limiting membrane peeling for myopic traction maculopathy. Am J Ophthalmol. 2012;154:693-701.

25.Ho TC, Chen MS, Huang JS, Shih YF, Ho H, and Huang YH. Foveola nonpeeling technique in internal limiting membrane peeling of myopic foveoschisis surgery. Retina. 2012;32:631-634.

26. Huang Y, Huang W, Ng DSC, and Duan A. Risk Factors for Development of Macular Hole Retinal Detachment after Pars Plana Vitrectomy for Pathologic Myopic Foveoschisis. Retina. 2017;37:10491054.

27. Hattori K, Kataoka K, Takeuchi J, Ito Y, and Terasaki H. Predictive Factors of Surgical Outcomes in Vitrectomy for Myopic Traction Maculopathy. Retina. 2018;38 Suppl 1:S23-S30.

28.Shimada N, Tanaka Y, Tokoro T, and Ohno-Matsui K. Natural course of myopic traction maculopathy and factors associated with progression or resolution. Am J Ophthalmol. 2013;156:948-957 e941.

29.Ikuno Y, and Tano Y. Vitrectomy for macular holes associated with myopic foveoschisis. Am J Ophthalmol. 2006;141:774-776.

30.Chen SN, Hwang JF, and Chen YT. Macular thickness measurements in central retinal artery occlusion by optical coherence tomography. Retina. 2011;31:730-737.

31.Hsu SY, and Tsai RK. Analysis of retinal nerve fiber layer and macular thickness measurements in healthy Taiwanese individuals using optical coherence tomography (Stratus OCT). J Glaucoma. 2008;17:30-35. 
32.Ooto S, Hangai M, Sakamoto A, Tomidokoro A, Araie M, Otani T, Kishi S, Matsushita K, Maeda N, Shirakashi M, Abe H, Takeda H, Sugiyama K, Saito H, Iwase A, and Yoshimura N. Three-dimensional profile of macular retinal thickness in normal Japanese eyes. Invest Ophthalmol Vis Sci. 2010;51:465473.

33.Shinohara K, Tanaka N, Jonas JB, Shimada N, Moriyama M, Yoshida T, and Ohno-Matsui K. UltrawideField OCT to Investigate Relationships between Myopic Macular Retinoschisis and Posterior Staphyloma. Ophthalmology. 2018;125:1575-1586.

34.Zhang T, Zhu Y, Jiang CH, and Xu GZ. Long-term follow-up of vitrectomy in patients with pathologic myopic foveoschisis. Int J Ophthalmol. 2017;10:277-284.

35.Ohno-Matsui K, Lai TY, Lai CC, and Cheung CM. Updates of pathologic myopia. Prog Retin Eye Res. 2016;52:156-187.

36.Cheng C, Teo K, Tan CS, Lee SY, Loh BK, Wong E, Wong D, Wong TY, and Cheung CM. MYOPIC RETINOSCHISIS IN ASIANS: Structural Features and Determinants of Visual Acuity and Prognostic Factors for Progression. Retina. 2016;36:717-726.

37.Gaucher D, Haouchine B, Tadayoni R, Massin P, Erginay A, Benhamou N, and Gaudric A. Long-term follow-up of high myopic foveoschisis: natural course and surgical outcome. Am J Ophthalmol. 2007;143:455-462.

38.Sun CB, Liu Z, Xue AQ, and Yao K. Natural evolution from macular retinoschisis to full-thickness macular hole in highly myopic eyes. Eye (Lond). 2010;24:1787-1791.

\section{Tables}

Table 1. Preoperative Clinical Data for Study Subjects with Macular Retinoschisis

\begin{tabular}{|c|c|c|c|c|c|c|c|}
\hline & \multicolumn{4}{|c|}{ Preoperative Type of Foveal Status } & \multicolumn{3}{|c|}{$\bar{P}$} \\
\hline & $\begin{array}{c}\mathrm{FS}(\mathrm{n}= \\
13)\end{array}$ & $\mathrm{FRD}(\mathrm{n}=12)$ & $\begin{array}{l}\text { LMH (n } \\
=12)\end{array}$ & $\begin{array}{l}\text { TOYAL (n } \\
=37)\end{array}$ & $\begin{array}{c}\text { FS vS } \\
\text { FRD }\end{array}$ & $\begin{array}{l}\text { FS vS } \\
\text { LMH }\end{array}$ & $\begin{array}{c}\text { LMH vs } \\
\text { FRD }\end{array}$ \\
\hline Sex, & M4 & M4 & M6 & M14 & $0.613 \dagger$ & $0.284 \dagger$ & $0.34 \dagger$ \\
\hline $\begin{array}{c}\text { Sex, eyes } \\
(\%)\end{array}$ & $\begin{array}{c}\text { F9 } \\
(69.2 \%)\end{array}$ & F8 (66.7\%) & $\begin{array}{c}\mathrm{F} 6 \\
(50 \%)\end{array}$ & $\begin{array}{c}\text { F22 } \\
(61.1 \%)\end{array}$ & & & \\
\hline Age, years & & & & & $0.922 *$ & $0.241 *$ & $0.174 *$ \\
\hline Range & $44-69$ & 47-65 & $51-68$ & 44-69 & & & \\
\hline Mean \pm SD & $\begin{array}{c}55.73 \pm \\
7.79\end{array}$ & $55.42 \pm 7.15$ & $\begin{array}{c}59.4 \pm \\
5.36\end{array}$ & $\begin{array}{c}56.66 \pm \\
6.95\end{array}$ & & & \\
\hline $\begin{array}{c}\text { Axial } \\
\text { length, } \mu \mathrm{m}\end{array}$ & & & & & $0.233^{*}$ & $0.238 *$ & 0.639* \\
\hline Range & $\begin{array}{l}28.02- \\
31.28\end{array}$ & $27-31.27$ & $\begin{array}{l}25.09- \\
33.35\end{array}$ & $\begin{array}{l}25.09- \\
33.35\end{array}$ & & & \\
\hline Mean \pm SD & $\begin{array}{r}29.65 \pm \\
1.35\end{array}$ & $28,73 \pm 1.47$ & $\begin{array}{c}28.3 \pm \\
2.47 \\
\end{array}$ & $\begin{array}{c}29.05 \pm \\
1.93 \\
\end{array}$ & & & \\
\hline
\end{tabular}


Note: *Kruskal-Wallis. †Chi-squared test. The difference in preoperative basic information among these three groups; FS: foveal retinoschisis; LMH: lamellar macular hole; FRD: foveal retinal detachment; BCVA, best-corrected visual acuity.

Table 2. Comparison of splitting subsidence in each group at four time points of 1, 3, 6 and 12 months after surgery

\begin{tabular}{|c|c|c|c|c|c|c|c|}
\hline & \multicolumn{3}{|c|}{ Preoperative Type of Foveal Status } & \multicolumn{4}{|c|}{$P$} \\
\hline & $\begin{array}{c}\mathrm{FS}(\mathrm{n}= \\
13)\end{array}$ & $\begin{array}{c}\text { FRD }(n= \\
12)\end{array}$ & $\begin{array}{c}\text { LMH (n }= \\
12)\end{array}$ & $\begin{array}{c}\text { TOYAL }(\mathrm{n}= \\
37)\end{array}$ & $\begin{array}{l}\text { FS vs } \\
\text { FRD }\end{array}$ & $\begin{array}{l}\text { FS vs } \\
\text { LMH }\end{array}$ & $\begin{array}{l}\text { LMH vs } \\
\text { FRD }\end{array}$ \\
\hline \multirow[t]{2}{*}{ Recovery within 1 months } & 7 & 1 & 6 & $0.034^{*}$ & $0.03 *$ & 0.582 & $0.034 *$ \\
\hline & $53.85 \%$ & $9.10 \%$ & $50 \%$ & & & & \\
\hline \multirow{2}{*}{$\begin{array}{l}\text { No recovery within } 1 \\
\text { months }\end{array}$} & 6 & 11 & 6 & & & & \\
\hline & $46.15 \%$ & $90.90 \%$ & $50 \%$ & & & & \\
\hline \multirow[t]{2}{*}{ Recovery within 3 months } & 12 & 3 & 9 & $\square 0.01 * *$ & $\square 0.01^{* *}$ & 0.322 & $0.039 *$ \\
\hline & $92.31 \%$ & $25.00 \%$ & $75.00 \%$ & & & & \\
\hline \multirow{2}{*}{$\begin{array}{c}\text { No recovery within } 3 \\
\text { months }\end{array}$} & 1 & 9 & 3 & & & & \\
\hline & $7.69 \%$ & $75.00 \%$ & $25.00 \%$ & & & & \\
\hline \multirow[t]{2}{*}{ Recovery within 6 months } & 13 & 9 & 10 & 0.169 & 0.096 & 0.22 & 0.5 \\
\hline & $100 \%$ & $75.00 \%$ & $83.33 \%$ & & & & \\
\hline \multirow{2}{*}{$\begin{array}{c}\text { No recovery within } 6 \\
\text { months }\end{array}$} & 0 & 3 & 2 & & & & \\
\hline & $0 \%$ & $25.00 \%$ & $16.67 \%$ & & & & \\
\hline \multirow{2}{*}{$\begin{array}{l}\text { Recovery within } 12 \\
\text { months }\end{array}$} & 13 & 10 & 12 & 0.198 & 0.22 & 1 & 0.478 \\
\hline & $100 \%$ & $83.33 \%$ & $100 \%$ & & & & \\
\hline \multirow{2}{*}{$\begin{array}{l}\text { No recovery within } 12 \\
\text { months }\end{array}$} & 0 & 2 & 0 & & & & \\
\hline & $0 \%$ & $16.67 \%$ & $0 \%$ & & & & \\
\hline
\end{tabular}

Note: ${ }^{*} P<0.05 ;{ }^{* *} P<0.01$; the difference in anatomic recovery among these three groups by chi-squared tests.

\section{Figures}




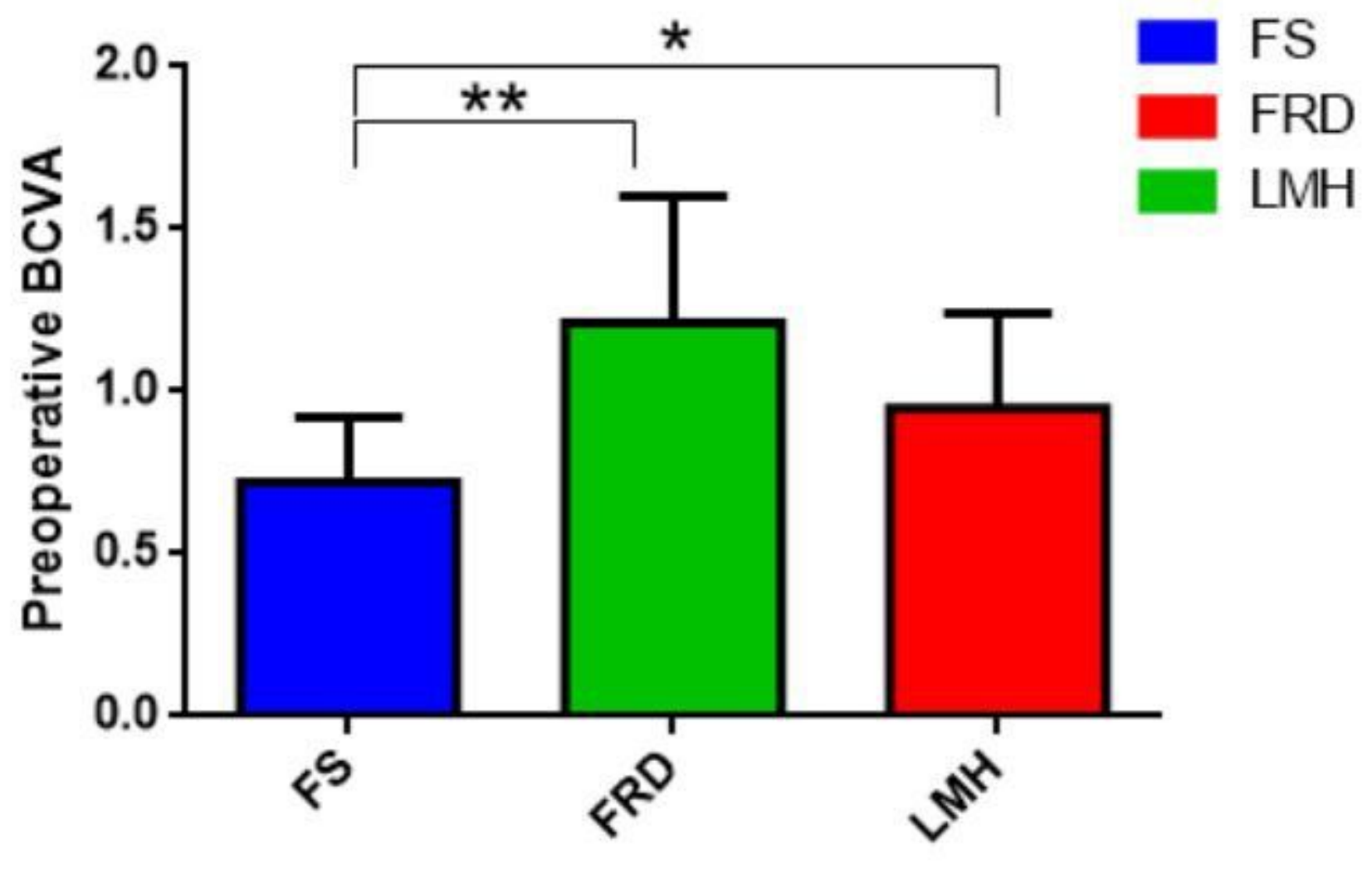

Figure 1

Differences in the Preoperative BCVA among the three groups Note: FS: foveal retinoschisis; LMH: lamellar macular hole; FRD: foveal retinal detachment; BCVA, best-corrected visual acuity; ${ }^{*} \mathrm{P}<0.05$; the difference of BCVA the three groups determined by the paired $t$ test. 


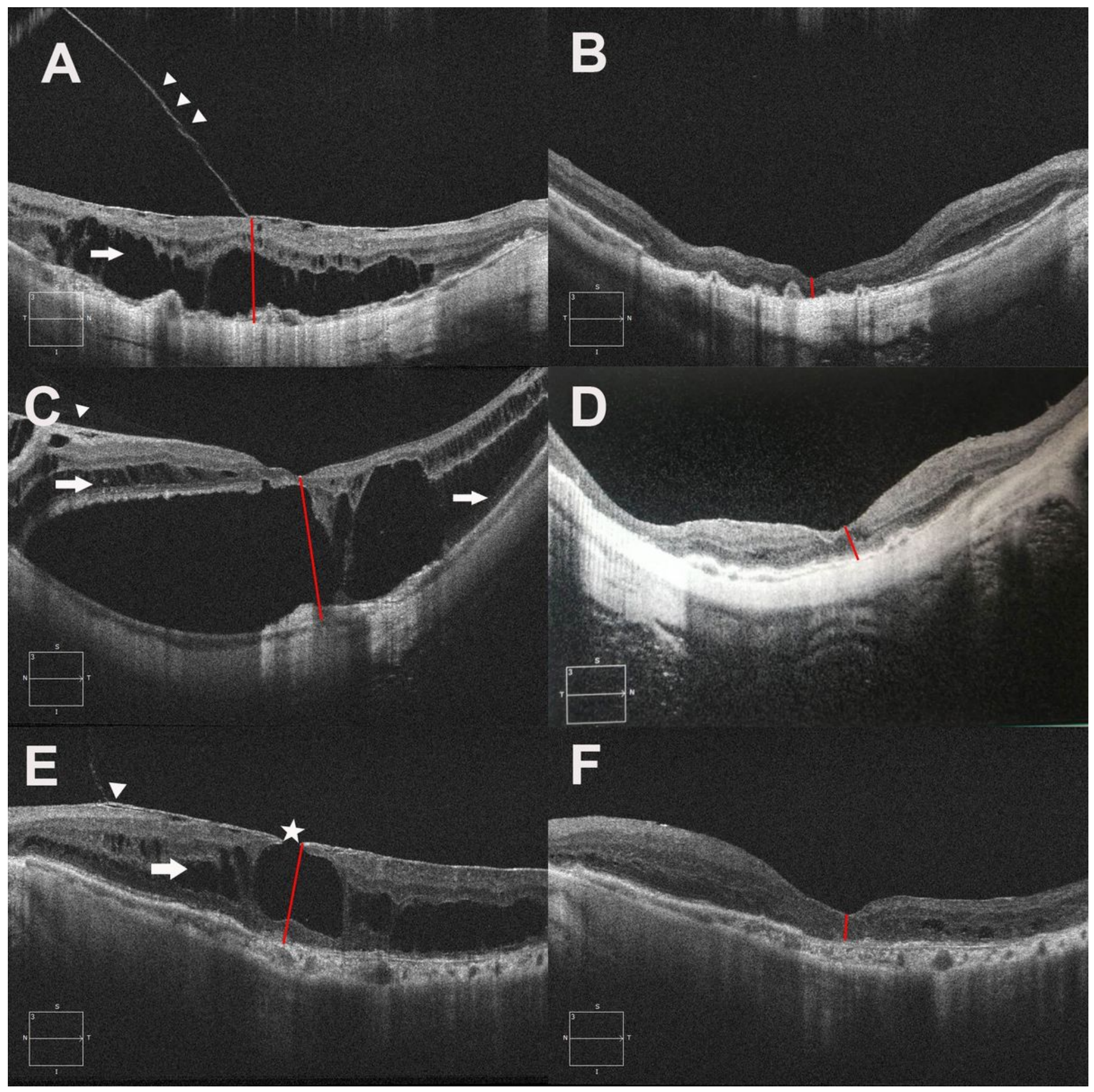

\section{Figure 2}

Typical OCT images of preoperative and postoperative splitting recovery in the FS, FRD, and LMH groups Note: A: Preoperative foveoschisis (FS) group. B: The retinoschisis of the FS group resolved 1 month after the operation. C: Preoperative foveal retinal detachment (FRD) group. D: The retinoschisis of the FRD group resolved 3 months after the operation. E: Preoperative lamellar macular hole (LMH) group: MTM is characterized by rupture of the retinal inner layer at the fovea (white pentagram). $F$ : The retinoschisis of the $\mathrm{LMH}$ group resolved 1 month after the operation. The red line indicates the splitting height measured 
in the fovea of the macula. A partially detached but intact Inner limiting membrane (ILM; white arrowheads) and stable macular retinoschisis (white arrows) can be seen preoperatively.

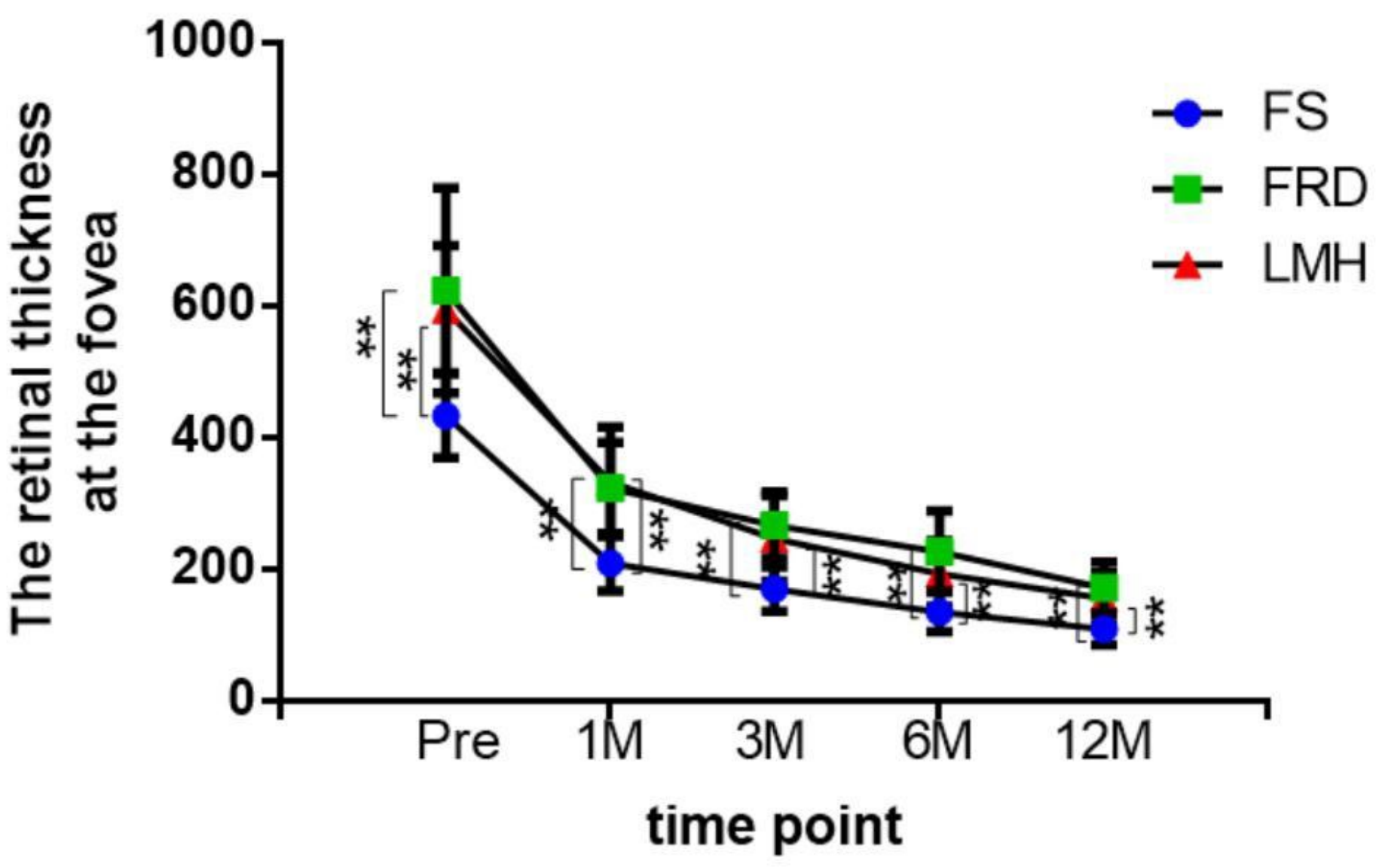

Figure 3

he mean CRT at different time points after vitrectomy for myopic foveoschisis in 36 eyes divided into three groups. Note: ${ }^{*} \mathrm{P}<0.05 ;{ }^{*} \mathrm{P}<0.001$; differences in the splitting height of the three groups determined by paired $t$ test. $M=$ months; $P r e=$ preoperative 

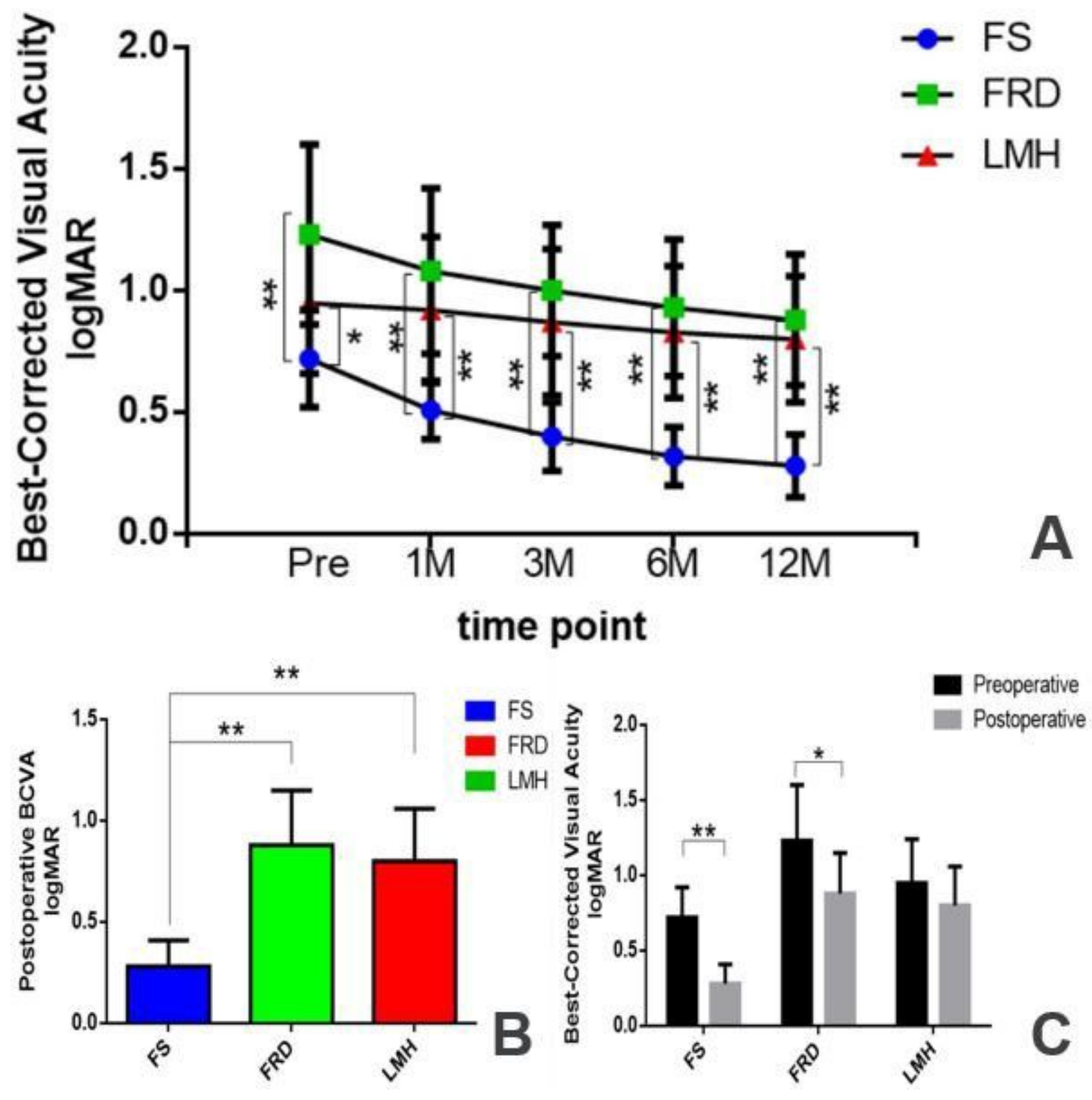

Figure 4

The changes in the BCVA of all three groups. Note: A: The mean changes in the BCVA at different time points after vitrectomy for myopic foveoschisis in 36 eyes of three groups. B: Differences in the postoperative BCVA among the three groups. C: Comparison of changes in the pre-and 12 months postoperative BCVA among the three groups. ${ }^{*} \mathrm{P}<0.05$; ${ }^{*} \mathrm{P}<0.01$; the differences in the BCVA among the three groups as determined by the $t$ test. $M=$ months; $P r e=$ preoperative. $F S$ : foveal retinoschisis; LMH: lamellar macular hole; FRD: foveal retinal detachment; BCVA, best-corrected visual acuity. 